Revista Qualidade Emergente, 2015, V. 6, N. 1:27-40

\title{
PRODUÇÃO AGROECOLÓGICA DE HORTALIÇAS NO ASSENTAMENTO CONTESTADO, MUNICÍPIO DA LAPA, PARANÁ.
}

Ademir de Jesus Riepe

Graduado em Tecnologia em Agroecologia - IFPR. Gestor em Projetos de Produção Agropecuária, pela Cooperativa Central deReforma Agrária Ltda. Endereço Eletrônico: ademirjiepe@gmail.com

Orientador: Paulo Eduardo Sobreira Moraes

Professor da Universidade Federal do Paraná (UFPR), Setor de Educação Profissional e Tecnológica.

Endereço Eletrônico: paulomoraes@ufpr.br

\section{Resumo}

O presente artigo analisa o processo de produção e qualidade de hortaliças em sistema agroecológico, bem como seus impactos socioeconômico e ambientais. Foi realizado a partir de experiência concreta no Assentamento Contestado, localizado na zona rural do município da Lapa, região sul do estado do Paraná. Através de observação direta e entrevistas com os participantes da ação, verificou-se que o sistema agroecológico promove o desenvolvimento socioeconômico, combinando preservação dos recursos naturais, com a produção de alimentos em quantidade, variedade e qualidade, e contribui para a saúde e qualidade de vida da população do campo e da cidade.

PALAVRAS CHAVE: qualidade na produção agroecológica, desenvolvimento local, meio ambiente.

\section{Abstract}

The present article analyzes the process of production and vegetables quality of in system agroecological, and their impact socioeconomic and environmental. Was realized starting of concrete experience in the settlement Contestado, situated in rural area of county of Lapa, region south of state of Paraná. Through to direct observation and interviews with participants of the action, it was found that the agroecological system promotes socioeconomic development, combining preservation of natural resources with food production in quantity, variety and quality, and contributes to the health and quality of 
life population of the countryside and city.

\section{Word - key: Quality in agroecological production, local development, environment preservation.}

\section{INTRODUÇÃO}

A ausência de canais para a comercialização dos produtos da agricultura familiar, bem como, a falta de informações e capacitação dos agricultores caracteriza um dos principais entraves ao desenvolvimento sustentável de comunidades rurais. Isso resulta em baixa produtividade, baixo nível de renda, e consequentemente em precárias condições de vida no campo.

Por outro lado, suas práticas de produção na maioria das vezes são desencadeadas incorretamente e aceleram o processo de degradação ambiental. Contudo, a realidade pode ser outra, pois agricultores familiares costumam diversificar a produção de alimentos e, quando orientados corretamente podem produzir alimentos em quantidade, diversidade e qualidade por meio de práticas de produção que minimizam a degradação dos recursos naturais.

Exemplo disso foi constatado no Assentamento Contestado localizado no município da Lapa, estado do Paraná. Nesta comunidade rural, cerca de 80 famílias atuam na produção agroecológica de hortaliças. E viabilizam-se economicamente por meio da comercialização direta ao consumidor e por meio de programas institucionais do Governo Federal, que garantem a compra da produção com o proposito de doar a diversas entidades filantrópicas e escolas de Curitiba, Campo Largo e Lapa, todas no estado do Paraná.

\section{O que é agroecologia?}

Segundo Miguel Altieri (1989), a "agroecologia constitui um enfoque teórico e metodológico que, lançando mão de diversas disciplinas científicas, pretende estudar a atividade agrária sob uma perspectiva ecológica". Ela adota o agroecossistema como unidade fundamental de análise, tendo como propósito proporcionar as bases científicas necessárias para a implementação de agriculturas mais sustentáveis.

Para Caporal e Costabeber (2004) a agroecologia se refere a um campo da ciência que aporta conhecimentos teóricos e metodológicos no estudo das experiências de agricultura alternativa. É entendida como um enfoque científico destinado a apoiar a 
transição dos atuais modelos de desenvolvimento rural e de agricultura convencionais para estilos de desenvolvimento rural e de agriculturas sustentáveis.

Como ciência, a Agroecologia apresenta uma série de princípios, conceitos e metodologias que permitem o estudo, a análise, o desenho, o manejo e a avaliação de agroecossistemas (ALTIERI, 1989).

Gliessman (2005) apresenta seis dimensões que sem as quais a sustentabilidade não é alcançada em agroecossistemas de produção;

$1^{\circ}$ refere-se à dimensão Ecológica, a qual não se restringe apenas as melhorias das condições físicas, químicas e biológicas do solo, mas também na manutenção e melhoria da biodiversidade, das reservas e mananciais hídricos, assim como dos recursos naturais em geral.

$2^{\circ}$ refere-se à dimensão Social, de modo que "a preservação ambiental e a conservação dos recursos naturais, adquirem relevância, quando o produto gerado nos agroecossistemas, possam ser apropriado e usufruídos pelos diversos seguimentos da sociedade".

3ำ refere-se à dimensão Econômica, de forma que a sustentabilidade de agroecossistemas supõe a necessidade de obterem-se balanço agro energético positivo, sendo necessário compatibilizar a produção agropecuária e o consumo de energias não renováveis.

4ํㅜ refere-se à dimensão Cultural, que numa intervenção em bases agroecológicas consideram-se os saberes, os conhecimentos e os valores locais das populações rurais.

$5^{\circ}$ se refere à dimensão Política, que tem a ver com os processos participativos e democráticos que se desenvolvem no contexto da produção agrícola e do desenvolvimento rural.

6ำ refere-se à dimensão Ética, que requer a adoção de valores, que não necessariamente serão homogêneos. Como o resgate da cidadania e da dignidade humana, a luta contra a miséria e a fome ou a eliminação da pobreza e suas consequências sobre o meio ambiente.

Miguel Altieri (1989) salienta que a sustentabilidade somente poderá ser alcançada no contexto de uma organização social que proteja a integridade dos recursos naturais e estimule a interação harmônica entre os seres humanos, o agroecossistema e o ambiente. Entrando a Agroecologia como suporte e com "as ferramentas metodológicas necessárias para que a participação da comunidade venha a se tornar a força geradora dos objetivos e atividades dos projetos de desenvolvimento rural sustentável". 


\section{O que é Agricultura Orgânica?}

No Brasil, a lei ํo 10.831, de 23 de Dezembro de 2003, caracteriza o sistema orgânico de produção na seguinte forma:

Considera-se sistema orgânico de produção agropecuária todo aquele em que se adotam técnicas específicas, mediante a otimização do uso dos recursos naturais e socioeconômicos disponíveis e o respeito à integridade cultural das comunidades rurais, tendo por objetivo à sustentabilidade econômica e ecológica, a maximização dos benefícios sociais, a minimização da dependência de energia não renovável, empregando, sempre que possível métodos culturais, biológicos e mecânicos, em contraposição ao uso de materiais sintéticos, a eliminação do uso de organismos geneticamente modificados e radiações ionizantes, em qualquer fase do processo de produção, processamento, armazenamento, distribuição e comercialização, e a proteção do meio ambiente. (BRASIL. Presidência da República, 2003).

Segundo Darolt (2007) a agricultura orgânica busca o equilíbrio nas técnicas de produção para chegar o mais próximo possível do que acontece na natureza. As práticas utilizadas nas propriedades orgânicas apontam para o convívio inteligente com a natureza. Elas devem promover o uso saudável do solo, da água e do ar, e reduzir ao mínimo todas as formas de contaminação e degradação desses recursos naturais. Além disso, deve promover a reciclagem de resíduos orgânicos, reduzindo ao mínimo o emprego de recursos não renováveis.

Para Buainain (2006) a produção alternativa não é uma volta ao passado; é um passo em direção ao futuro, baseia-se no desenvolvimento da ciência e na aplicação de conhecimento científicos. Não é puro produto do saber camponês, requer capacitação dos recursos humanos que não está disponível nos manuais e não é conversível em bulas de recomendações feitas pelos extensionistas.

O alimento orgânico é isento de insumos artificiais como os fertilizantes sintéticos e os agrotóxicos, de drogas veterinárias, hormônios e antibióticos, e de organismos geneticamente modificados. Durante o processamento dos alimentos é proibido o uso das radiações ionizantes e aditivos químicos sintéticos (BRASIL, 2003).

Para um alimento de origem vegetal ou animal ser comercializado como orgânico é necessário que o sistema de produção esteja credenciado em uma das agencias de Certificação de Orgânicos, a qual disponibilizará ao agricultor o Certificado de produtor orgânico, que significa garantir a procedência, a rastreabilidade e a qualidade orgânica 
dos produtos (BRASIL, 2003).

Segundo Santos (2004) para se tornar um agricultor orgânico é necessário que o candidato seja submetido a um rigoroso processo de investigação das condições ambientais do estabelecimento agrícola e de potencialidade para a produção. São considerados aspectos como o não uso de agrotóxicos nos últimos dois anos, a existência de cerca viva quando há vizinhos que praticam agricultura convencional, a qualidade da água utilizada na irrigação e na lavagem dos alimentos, as condições de trabalho e de vida dos trabalhadores, o cumprimento da legislação sanitária e a existência de lixo espalhado pelo estabelecimento, dentre outros.

A entidade que desenvolve a certificação deve estar credenciada junto ao Ministério da Agricultura, Pecuária e Abastecimento MAPA, e acreditada pelo Instituto Nacional de Metrologia, Normalização e Qualidade Industrial (Inmetro) conforme estabelece o artigo 36 do decreto $\mathrm{n}^{\circ} 6.323$ de 27 de dezembro de 2007 (BRASIL, 2007).

\section{Segurança alimentar e Saúde}

Segundo Darolt (2003) a ANVISA (Agência Nacional de Vigilância Sanitária) em parceria com a Fiocruz (Fundação Oswaldo Cruz) mostrou que $22,17 \%$ de frutas, verduras e legumes, produzidos em sistema convencional, e vendidos em supermercados em quatro Estados (São Paulo, Paraná, Minas Gerais e Pernambuco) apresentavam irregularidades graves, ou seja, com agrotóxicos acima do limite permitido pela legislação e produtos não autorizados pela alta toxicidade.

O mesmo autor destaca que produzir alimentos completamente livres de substâncias tóxicas tornou-se um grande desafio. A considerar que os herbicidas utilizados para controle de plantas daninhas no sistema convencional, apresentam um baixo peso molecular, tendo grande poder de difusão no meio ambiente. Darolt (2003) citando Higashi lembra que estas moléculas podem se deslocar por uma distância de até $30 \mathrm{~km}$. Por isso, o risco de contaminação por resíduos de produtos químicos é reduzido em alimentos orgânicos, mas ele existe, em função de poluentes persistentes no meio ambiente e derivação de produtos utilizados na agricultura convencional.

STERTZ \& SCUCATO (2001) analisando 23 amostras de hortifrutigranjeiros orgânicos (abóbora, alface, batata, mandioquinha-salsa, berinjela, beterraba, caqui, cenoura, couve, couve-flor, morango pepino, pimentão, rabanete, repolho e tomate) verificaram a presença de organoclorados, organofosforados, piretróides, carbamatos, benzoimidazóis e ditiocarbamatos. Os resultados mostraram que a totalidade das amostras 
pesquisadas não apresentou resíduos para os princípios ativos pesquisados, o que comprova a qualidade dos produtos orgânicos.

\section{Agricultura Familiar e Alimentação}

No Brasil, a agricultura familiar corresponde a 4.367 .902 estabelecimentos, representando $84 \%$ dos estabelecimentos, com exploração de $24,3 \%$ da área total dos estabelecimentos agropecuários. Sua produção bruta contribui anualmente com aproximadamente 54 bilhões de reais, caracterizando-se pela principal fornecedora de alimentos básicos para a alimentação dos brasileiros, sendo responsável pela produção de $87 \%$ da mandioca, $70 \%$ do feijão, $46 \%$ do milho, $38 \%$ do café, $34 \%$ do arroz, $21 \%$ do trigo, $16 \%$ da soja. Além disso, é importante fornecedora de proteína animal, garantindo 49,25\% do leite, aves, suínos e bovinos, (IBGE, 2006).

Segundo estudos das Nações Unidas, publicadas em 2001, citados por Mazoyer (2010), o planeta contará no ano 2050, com aproximadamente nove bilhões de seres humanos. Destaca ainda que "apenas para alimentar corretamente uma determinada população, sem subnutrição nem carência, a quantidade de produtos vegetais destinados à alimentação dos homens e dos animais terá que dobrar no mundo inteiro". Devendo triplicar nos países em desenvolvimento, mais que quintuplicar na África e mesmo aumentar dez vezes mais em muitos países desse continente.

O mesmo autor destaca que para promover as agriculturas camponesas sustentáveis, capazes de assegurar, em quantidade e qualidade, a segurança alimentar de seis e, muito em breve, nove bilhões de seres humanos, é preciso antes de tudo, garantir aos camponeses preços suficientemente elevados e estáveis para que eles possam viver dignamente de seu trabalho.

Segundo Freire (1997) é necessário "o direcionamento de ações e atividades que promovam novos estilos de desenvolvimento e de agricultura, que respeitem não só às condições especificas de cada agroecossistema, mas também a preservação da biodiversidade e da diversidade cultural".

Para Buainain (2006) "o futuro da agricultura familiar depende da capacidade de produzir produtos diferenciados, de aproveitar-se das oportunidades que vêm se abrindo nos mercados, de elevar o valor por unidade produzida". Para o autor, estabelecimentos de produção agrícola familiar, normalmente de pequeno porte, podem explorar melhor a produção de produtos diferenciados e ecologicamente corretos, a exemplo dos sistemas orgânicos de produção.

Por outro lado, cresce permanentemente o interesse de consumidores em terem acesso aos alimentos orgânicos e agroecológicos, ganhando força a consciência pela busca de uma alimentação saudável (BUAINAIN, 2006). Por outro lado há a necessidade de fortalecer a agricultura familiar, e a produção agroecológica melhor se adapta a esse seguimento. 


\section{MATERIAL E METODOS}

Esse estudo foi realizado por meio da metodologia de estudo de caso, com trabalho de campo, que versou sobre a coleta de dados em situação real, por meio de observação direta e entrevista com os participantes da ação. O questionário com perguntas semi estruturadas e abertas foi aplicado a cinco lideranças locais e a cinco agricultores. Foi realizado no mês de abril do ano 2012.

O Assentamento contestado está localizado no município da Lapa, estado do Paraná, a $70 \mathrm{~km}$ da capital Paranaense. Foi consolidado em 1998 pelo Programa Nacional de Reforma Agrária, beneficiando diretamente cento e oito famílias, das quais, oitenta atuam na produção de alimentos por meio do sistema orgânico.

Cada família possui em média 12 hectares de terra. Possuem casas de alvenaria, com água encanada, e energia elétrica. Contam com estradas de boa qualidade com acesso a todas as moradias.

Com escola no próprio assentamento, as crianças e jovens, tem acesso à educação formal que possibilita conclusão do ensino médio na própria comunidade. Conta ainda com a Educação de Jovens e Adultos - EJA, destinado às pessoas que não puderam concluir o ensino médio.

A população local viabiliza-se economicamente por meio da produção e comercio de hortifrúti, leite e seus derivados, pequenos animais e mel, com orientação especial para o sistema agroecológico de produção.

\section{RESULTADOS E DISCUSSÃO}

Segundo Capitani, agricultor assentado e membro da cooperativa local, no período de 1999 a 2002 o conjunto de famílias ali residentes aderiram ao sistema convencional de produção, com a exploração comercial de soja, milho, feijão e leite. Esse período foi marcado por crises, com baixos índices de produtividade, consequentemente baixo desenvolvimento econômico, o que culminou na evasão de muitas famílias, que deixaram o campo para morar na cidade.

Por meio de pesquisa nos arquivos internos da associação, constatou-se que no referido período foram produzidos aproximadamente 2.000 sacas de feijão, 4.000 sacas de milho, 2.500 sacas de soja, 108.000 litros de leite, 18.250 quilos de queijo. Todo o comercio da produção era realizada por meio de atravessadores situados na Lapa e Balsa Nova.

Celso chagas, agricultor ecológico salienta que as famílias assentadas, em sua maioria são oriundas da região oeste e sudoeste do Paraná, e que quando assentadas no referido local, trouxeram consigo os conhecimentos de agricultura praticados nestas 
regiões. Que consistia na exploração comercial de culturas de ciclo longo, a exemplo da soja e do milho, no sistema convencional de produção. Contudo, essa prática foi inviabilizada, dada a crescente demanda de agroquímicos e máquinas, algo que está fora do alcance dos agricultores familiares.

\section{A busca por novas práticas de produção agrícola e comércio}

Diante da dificuldade para garantir o desenvolvimento socioeconômico local por meio do sistema convencional de produção, com a exploração comercial de culturas de ciclo longo, algumas famílias começam a desenvolver a produção agropecuária de acordo com os princípios da agricultura orgânica, após participar de cursos de capacitação para tal.

Ao longo de poucos anos houve ampla redução na produção de culturas de ciclo longo, em função da aderência à produção de leite e seus derivados, bem como à produção de hortifrúti no sistema orgânico que tem se caracterizado como principal linha de produção até os dias atuais.

No processo de reconstrução da agricultura local, Mário, agricultor ecológico destaca que o Programa de Aquisição de Alimentos - PAA caracterizou o principal motivador à mudança de conduta dos agricultores, pois possibilitou e tem possibilitado a garantia de comercio aos diversos produtos, a preços que garantem o desenvolvimento socioeconômico local, aliando a produção com a preservação dos recursos naturais.

É relatado que o desenvolvimento da agroecologia no assentamento é decorrente de uma série de fatores. Dentre eles a conscientização das famílias em relação aos danos que os agrotóxicos causam a saúde e ao meio ambiente. A superação de problemas sociais e políticos que marcaram o início do assentamento. Os trabalhos de assessoria técnica e extensão rural aplicada em diversas atividades e na formação dos agricultores, e a superação de entraves que envolvem desde 0 ato de produzir 0 alimento até a sua inserção no mercado.

\section{Consolidação do sistema agroecológico de produção}

A partir de 2003 adotou-se no assentamento contestado a agroecologia como estratégia de desenvolvimento local. As ações de agricultura no local passaram a ser orientadas para o uso eficiente e consciente dos recursos naturais. $\mathrm{O}$ uso de agrotóxicos e fertilizantes químicos no processo produtivo é extinto e a carência de energia na agricultura passou ser suprida pela compostagem, adubação verde, produtos homeopáticos, além de adubo ecológico certificado, que é adquirido externamente.

As famílias contam com orientação especializada de profissionais qualificados em produção ecológica, vinculados à Empresa de Assistência Técnica e Extensão Rural EMATER/PR. Realizam permanentemente cursos sobre boas práticas de produção, 
manejo alternativo de pragas e doenças, adequação de unidades produtivas para o processo de certificação, intercâmbios para conhecimentos de experiências em olericultura e fruticultura.

Atualmente trinta e nove famílias possuem o selo de produtor orgânico, conferido pela Rede Eco vida de Agroecologia, na modalidade certificação participativa. Outras 50 famílias e suas respectivas unidades de produção estão em processo de certificação por auditoria externa, realizada pelo Centro de Tecnologia do Paraná - TECPAR. Do total de famílias assentadas na comunidade, apenas 15 produz no sistema convencional, especialmente soja, milho e leite.

\section{Qualidade na produção agroecológica}

Atender as normas expressas na lei no 10.831 de 23 de Dezembro de 2003 que dispõe sobre produção orgânica é a base para a garantia de qualidade nos alimentos. E no Assentamento Contestado isso é condição para a permanência do agricultor no grupo de produtor ecológico credenciados pela Rede Ecovida de Agroecologia e pelo Tecpar.

A referida comunidade está organizada em dez grupos, cada um com dez famílias. Dos quais, nove grupos que totaliza noventa famílias realiza a produção de alimentos sub o sistema agroecológico. Cada grupo tem um coordenador, o qual juntamente com os demais coordenadores, formam uma equipe de auditoria com o objetivo de auxiliar a Rede Ecovida na realização dos trabalhos para a certificação e monitoramento do processo produtivo, atividade realizada permanentemente.

Mensalmente os grupos se reúnem para discutir questões pertinentes à comunidade. As reuniões ocorrem em locais alternados, nas unidades de produção familiar, ou seja, a cada mês é realizada reunião em uma propriedade. Desta forma, antes ou depois da reunião, todos os integrantes do grupo se dirigem às instalações e aos campos de produção, objetivando averiguar se as normas de produção orgânica/agroecológica estão sendo atendidas.

O reconhecimento demandado pelos assentados que produzem no sistema agroecológico é a credibilidade acreditada pelo consumidor. Isso envolve a participação de todos os envolvidos e interessados na produção dos alimentos. A certificação tem sido trabalhada como um processo pedagógico em que agricultores, técnicos e consumidores integram-se para buscar expressão pública da qualidade.

Cada agricultor é responsável por garantir a qualidade e a conformidade dos alimentos por ele produzidos, por meio de práticas ecologicamente corretas, que resultam em alimentos com qualidade biológica superior, livres de qualquer tipo de subsistência química que possa causar danos à saúde dos consumidores e ao meio ambiente.

Para garantir a integridade e a qualidade biológica dos alimentos, a coleta na lavoura é realizada a partir das três horas da tarde do dia anterior à entrega ao consumidor. Cada 
agricultor realiza esta operação na sua unidade de produção, a qual envolve a coleta, seleção, limpeza e acomodação nas caixas plásticas.

Para entrega dos alimentos ao consumidor, a qual é realizada uma vez por semana, uma equipe de cinco pessoas realiza a coleta dos alimentos, em um caminhão, a partir das quatro horas da tarde do dia anterior, nas respectivas unidades de produção previamente agendadas. A entrega ao consumidor final é realizada a partir das 07h30min da manhã.

Pelo PAA são comercializadas anualmente 242 (duzentas e quarenta e duas) toneladas de alimentos, com mais de 90 variedades vegetais, especialmente hortifrúti. São beneficiadas diretamente 97.025 pessoas vinculadas às diversas entidades que recebem alimentos por meio do PAA, na cidade da Lapa, Campo Largo e Curitiba.

O mercado de alimentos é exigente em múltiplos fatores, merecendo especial atenção à qualidade e a conformidade, além da garantia de regularidade no fornecimento, desta forma, os agricultores precisam estar atentos a estas exigências. E é justamente por isso que as famílias do assentamento contestado incorporaram mais um desafio local, que se refere ao beneficiamento mínimo de hortifrúti.

Para isso estrutura-se uma agroindústria, a qual absorverá toda a produção disponível no assentamento. Conforme relato, espera-se processar, melhorar a qualidade e agregar valor aos alimentos com vistas à satisfação dos consumidores, bem como, conquistar novos mercados.

\section{Gestão Comercial}

Para o escoamento da produção, os assentados contam com a COOPERATIVA TERRA LIVRE, com sede no próprio assentamento. A qual tem o objetivo de auxiliar no desenvolvimento socioeconômico local, através da organização da produção e do comercio. Conta atualmente com 121 sócios, dos quais 114 são assentados da reforma agrária, e sete são quilombolas que residem no entorno do assentamento.

Atualmente o Programa de Aquisição de Alimentos - PAA, na modalidade Compra da Agricultura Familiar com Doação Simultânea e o Programa de Alimentação Escolar, são os principais canais de comercialização da produção agrícola local, em especial hortaliças como; alface, almeirão, repolho, rúcula, cheiro verde, pimentão, abobora, tomate, mandioca, batata doce, cenoura, beterraba, dentre outros, que totalizam a quantia de 90 variedades vegetais.

O PAA é uma das ações do Programa Fome Zero do Governo Federal e tem como objetivo garantir o acesso a alimentos em quantidade e regularidade necessárias às populações em situação de insegurança alimentar e nutricional. Visa contribuir também para formação de estoques estratégicos e permitir aos agricultores familiares que armazenem seus produtos para que sejam comercializados a preços mais justos, além de promover a inclusão social no campo (MDA, 2012). 
Por meio do PAA é realizada entrega de alimentos semanalmente a cinco entidades em Curitiba (Liga Paraense de Combate ao Câncer - Hospital Erasto Guetner), APAE, Rede Solidária de Alimentos, Centro de Formação Urbana e Rural Irmã Araújo - CEFURIA, Ação social do Paraná, e uma no município da Lapa - Instituto Contestado de Agroecologia, além de uma escola no município de Araucária, pelo Programa Nacional de Alimentação Escolar - PNAE. Também é realizada a comercialização direta ao consumidor por meio de feira na cidade da Lapa.

Segundo relato a participação neste programa tem possibilitado a discussão de alternativas à produção de grãos, prática de cooperação entre assentados (as), organização da cadeia produtiva, melhoria da qualidade dos produtos comercializados, agro industrialização, capacitação e estruturação da logística de distribuição.

\section{CONSIDERAÇÕES FINAIS}

O mercado institucional na modalidade PAA - Doação Simultânea apresenta uma limitação de $\mathrm{R} \$ 4.800,00$ por família ao ano. Já o Programa de Alimentação Escolar PNAE garante retorno de $R \$ 20.000,00$ por família ao ano, porém a participação dos agricultores tem sido limitada, em função de a maioria das escolas públicas não disporem de condições estruturais para o armazenamento dos alimentos, o que exige a realização de várias entregas em uma mesma semana, resultando em alto custo para a cooperativa.

Ambas as modalidades de comercio institucional garantem retorno financeiro importante, sobretudo por dissociar o produto convencional do agroecológico. Alimentos certificado recebe valor $30 \%$ a mais em relação ao alimento convencional. No entanto, destaca-se a importância para o desenvolvimento local, a conquista de novos mercados, com canais de escoamento da produção seguros, evitando assim a dependência dos programas institucionais para comercialização dos alimentos.

Desta forma é importante a estruturação de unidade para beneficiamento mínimo, como forma de agregar valor e obter maior aceitação no comercio. Além disso, é importante a aplicação de ferramentas de Gestão da Qualidade, como forma de melhorar continuamente o processo e atender ao mercado que é exigente em termos de qualidade e conformidade. Sugere-se difundir junto aos agricultores a ferramenta Autocontrole para assegurar a verificação técnica na produção, a qual poderá ser realizada nas próprias unidades de produção, pelos agricultores, e pela equipe que realiza a coleta.

As famílias do Assentamento Contestado, além de desenvolver a produção agroecológica, tem realizado um importante trabalho com a medicina popular; com o cultivo e uso de plantas medicinais, e o tratamento bioenergético.

A Reserva Legal encontra-se inteiramente preservada, a qual se localiza em área coletiva. Cada família é responsável por preservar ou recuperar a Área de Preservação Permanente - APP no entorno de rios e nascentes, que também se encontra preservada. 


\section{CONCLUSÃO}

Constatou-se na comunidade pesquisada a constante preocupação com a segurança alimentar e nutricional como forma de promover a saúde e a qualidade de vida. Destaca ainda a emergência continua de consciência ecológica, a qual é visualizada em questões como a preocupação com a preservação dos solos, das áreas de preservação permanente e da reserva legal, proteção da fauna e da flora, redução da entrada de imputes externo, dentre outros.

Constata-se que o sistema de produção agroecológico soma-se às estratégias de desenvolvimento sustentável, visto que promove o desenvolvimento local, aliando a produção de alimentos em quantidade, variedade e qualidade, com a preservação dos recursos naturais, e possibilita o desenvolvimento de novas relações sociais no campo, e destes com os consumidores, realidade constatada na referida comunidade.

A forma como é realizada a produção dos alimentos, confere ao consumidor a segurança de que está adquirindo produtos com origem em um sistema de produção que preza pela saúde e à qualidade de vida da população, e pela proteção e conservação do meio ambiente. Além de possibilitar a inclusão social e o desenvolvimento na agricultura familiar.

Para o agricultor, o sistema agroecológico de produção permite a geração de renda em áreas relativamente pequena, uma vez comparado ao sistema convencional de produção, pois permite o cultivo de diversas variedades para fins comerciais, como é o caso da produção de hortifrúti. Além disso, promove a saúde e a qualidade de vida dos agricultores, em função do não uso de agroquímicos no processo produtivo, e possibilitar ao produtor o consumo de alimentos variados, em quantidade, variedade e qualidade nutricional, oriundo de sua própria produção.

Visualiza-se imensa capacidade de os agricultores produzirem quantidades superiores de alimentos, porém, o processo se limita em função da falta de condições estruturais para o beneficiamento mínimo dos alimentos, o que possibilitaria maior aceitação nas redes de distribuição de alimentos, especialmente em Curitiba PR.

\section{REFERÊNCIAS}


ALTIERI, Miguel A. et. al. Agroecologia: as bases científicas da agricultura alternativa. Edição AS-PTA Assessoria e Serviços a Projetos em Agricultura Alternativa. Rio de Janeiro, 1989, Segunda edição.

BUAINAIN, M. A. Agricultura familiar, agroecologia e desenvolvimento sustentável: questões para debate. Instituto Interamericano de cooperação para a agricultura, Brasília, 2006.

CAPORAL, F. R. \& COSTABEBER, J. A. Agroecologia: enfoque científico e estratégico. Agroecologia e Desenvolvimento Rural Sustentável, Porto Alegre, 2002.

FREIRE, Paulo. Extensão ou comunicação? Editora: Paz e Terra, 9o edição, Rio de Janeiro, 1997.

GLIESSMAN, S.R. Agroecologia: processos ecológicos em agricultura sustentável. Porto Alegre: Editora da Universidade - UFRGS $3^{\circ}$ ed. 2005.

MAZOYER, Marcel. História das agriculturas no mundo: do neolítico à crise contemporânea. Tradução de Cláudia F. Falluh Balduino Ferreira - São Paulo: Editora UNESP; Brasília, DF: NEAD, 2010.

SANTOS, G. C. Alimento e nutrição, V. 15, № 1. Faculdade de ciências farmacêuticas UNESP - Araraquara - São Paulo, 2004.

DAROLT, M. R. Comparação da qualidade do alimento orgânico com o convencional. Universidade Federal de Viçosa - UFV, 2003, p. 389 - 312.

DAROLT, M. R. Alimentos Orgânicos: Um guia para o consumidor consciente, $2^{\circ}$ ed. revisado. e ampliado. Instituto Agronômico do Paraná - Londrina, 2007.

STERTZ, S. C. \& SCUCATO, E. S. Análise de resíduos de agrotóxicos em alimentos orgânicos. Encontro regional Sul de ciência e tecnologia de alimentos, Anais, Curitiba, 2001.

Instituto Brasileiro de Geografia e Estatística - IBGE, Censo Agropecuário, Rio de Janeiro, p. 1 - 146, 2006.

Programa de Aquisição de Alimentos PAA. Disponível em: http://www.mda.gov.br/portal/saf/programas/paa, acessado em 05/05/2012.

LEI No 10.831, DE 23 DE DEZEMBRO DE 2003. Disponível em: http://www.planalto.gov.br/ccivil_03/leis/2003/10.831.htm. Acessado em 15/05/2012.

\section{TERMO DE APROVAÇÃO}


Ademir de Jesus Riepe

PRODUÇÃO AGROECOLÓGICA: O CASO DO ASSENTAMENTO CONTESTADO NO MUNICÍPIO DA LAPA, PARANÁ.

Este trabalho de conclusão de curso, modalidade Artigo Científico foi julgado adequado para a obtenção do título de especialista em GESTÃO SOCIOAMBIENTAL, e aprovado na sua forma final pela Faculdade de Ciências Sociais e Aplicadas do Paraná FACET.

Prof. Dr. Paulo Eduardo Sobreira Moraes Orientador

Prof. Dr. Roberto Ari Guindani Coordenador do Curso 